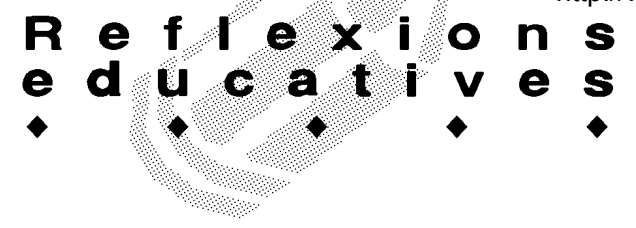

\title{
L'APRENENTATGE POLÍTIC DE LA PARTICIPACIÓ DEMOCRÀTICA
}

\author{
Antoni Santisteban. Àrea de Didàctica de les Ciències Socials
}

La participació política requereix una formació i una predisposició per intervenir en la vida pública. L'aprenentatge de la política es confon massa sovint amb l'adquisició de coneixements relatius als partits polítics, a les institucions o als sistemes de govern. Tot $\mathrm{i}$ la importància d'aquests continguts, val a dir que la cultura política s'adquireix, en primer lloc, a través d'experiències personals, que van configurant una determinada actitud envers l'entorn social i polític. La família, l'escola, el poble, el barri o la ciutat, són els ambients de socialització i, al mateix temps, d'aprenentatge de determinades formes de participació. El poder, el lideratge i les capacitats de decisió estan sempre en joc dins d'aquests contextos (vegeu també Santisteban, 1993 i Pagès i Santisteban, 1994).

\section{Per aprendre política contem amb tu!}

Els nens $\mathrm{i}$ nenes, nois i noies necessiten d'un ensenyament que els permeti reflexionar i analitzar tot el ventall de situacions que viuen a la seva vida quotidiana. $A$ l'educació primària cal introduir l'estudi dels grups de convivència de l'alumnat. A l'educació secundària cal aprofundir sobre qüestions relatives a la ciència política, sense oblidar que la vida diària dels joves està plena d'experiències que són les que configuren, amb més força, la seva concepció de la participació democràtica: el poder o el lideratge dins de la colla d'amics, l'organització participativa del club esportiu, etc.

Des d'una perspectiva constructivista de l'aprenentatge, el procés d'adquisició dels coneixements que permeten una formació en ciències socials per a la intervenció social, per a la responsabilitat i per a la llibertat, és un camí complex que surt del medi social més proper als nens i arriba a l'explicació de les relacions polítiques internacionals. Això no vol dir que el que és més proper sigui més fàcil d'entendre, sinó que el coneixement es construeix a partir d'allò més general $\mathrm{i}$ integrador. Aquest procés està representat per la formació d'esquemes de coneixement individuals, cada vegada més rics i més amplis, fruït de les nostres relacions en els diversos grups humans. Així, el concepte de poder, per exemple, es comença a formar en el context familiar o dels amics, i va madurant al llarg del temps, amb altres experiències, amb els aprenentatges d'altres formes de poder, i d'altres àmbits d'aplicació del concepte, com determinats tipus d'associacions a què podem pertànyer, o a través de l'anàlisi o de l'estudi de diferents sistemes d'organització social i política, com la ciutat, l'Estat, etc.

\section{Busquem problemes}

Un currículum crític de ciències socials ha de tenir en compte que les finalitats essencials dels aprenentatges de l'alumnat han de ser la comprensió de la realitat social, el desenvolupament de capacitats que facin possible aquesta difícil comprensió (pensament crític, resolució de problemes socials...), i, per últim, la voluntat de conèixer la societat per canviar-la, per miIlorar-la, per construir el futur. L'aprenentatge polític de la participació democràtica ha de tenir un enfocament crític, basat en la mateixa participació de l'alumnat a l'aula, fent-lo protagonista de la seva pròpia formació.

Per a l'aprenentatge polític de la participació democràtica és essencial el que Slaughter (1991) ha anomenat l'aprenentatge del futur. Es tracta d'ensenyar a construir el futur, distingint entre els futurs possibles, probables, desitjables, i fent projeccions de les nostres intencions. Es tracta, en definitiva, de creure que l'educació dels futurs ciutadans i ciutadanes s'ha de fer en funció de la seva futura participació social en la vida democràtica de la comunitat. Les eleccions polítiques, per exemple, s'han de llegir en clau de passat històric, però també de futur per escriure (Santisteban, 1995).

El currículum s'ha de basar en els problemes socials que conviuen amb la democràcia formal, problemes personals, problemes dels grups humans i de les comunitats. La temàtica que s'hauria de tractar ha d'estar relacionada amb la vida quotidiana de les persones, dels grups, dels marginats, de les contradiccions de la mateixa democràcia. Sembla que aquest és un camí per evitar que la democràcia sigui solament un sistema polític que funciona per defecte. La democràcia té sentit si la gent vota, però tant o més important és també que les persones participin o intervinguin socialment. 


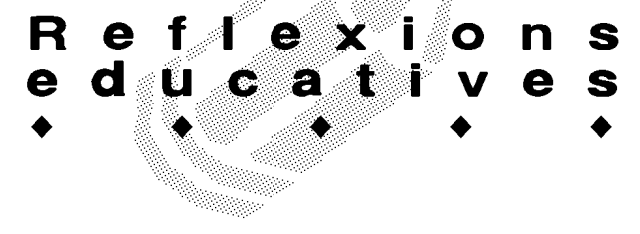

Aranguren (1963) ens recordava que la democràcia no és una possessió, sinó una aspiració. Com escriu Savater (1992), no s'ha de ser idiota, en l'accepció grega original de qui no es preocupava per allò que és públic.

\section{El germà, la mestra, Bill Clinton, la televisió}

Una manera d'organitzar els continguts socials des d'una perspectiva constructivista i crítica són els conceptes clau: identitat, interrelació, conflicte, organització, poder, canvi, creences, racionalitat.
Conceptes acceptats per les diferents ciències socials -història, geografia, història de l'art, sociologia, antropologia, política, economia, dret-, i que ajuden a saber què hem d'ensenyar. Els podem utilitzar per pensar com ensenyar la democràcia al llarg de l'educació obligatòria.

Identitat. Tothom pertany a un grup natural o a una comunitat, tothom forma la seva personalitat a través dels grups humans on conviu. Alguns d'aquests són associacions a les quals es pertany de manera voluntària.

\section{JO, TU... NOSALTRES}

\section{Companyes, col-legues, socis... No passeeu de mi!}

La vida és una contínua relació amb les persones que tenim al voltant: unes són familiars, altres amigues, uns són veïns, altres socis en una empresa comuna, uns ens ajuden i altres són competidors que ens fan la traveta, però les persones solament poden viure en comunitat $i$ en convivència. Fem una mirada a les persones que tenim al voltant.

Observa les següents il//ustracions:

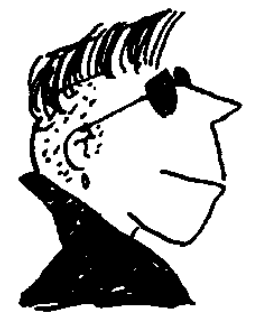

Aquest xicot es diu Pau, estudia primer d'Arquitectura i li agrada passar desapercebut.

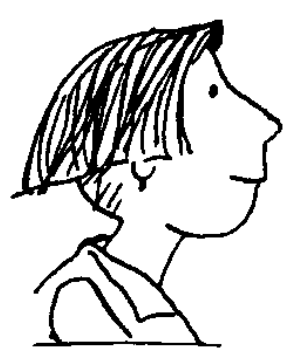

L'Anna és la cantant d'un grup musical de rock dur. Actua cada cap de setmana i sempre té problemes, ja que tots els seus concerts acaben amb baralles entre el públic.

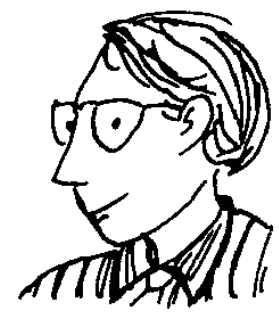

En Josep és un noi molt problemàtic, fa temps va deixar els estudis, va marxar de casa seva i ara recull cartons.

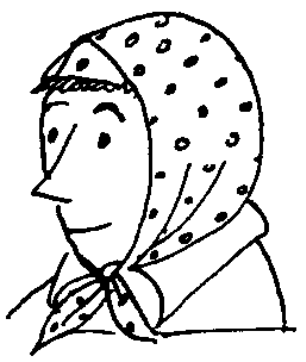

La Sara és la capitana de l'equip de bàsquet del seu institut. Ara surt amb un noi que es diu Franc i sembla que la relació és seriosa.

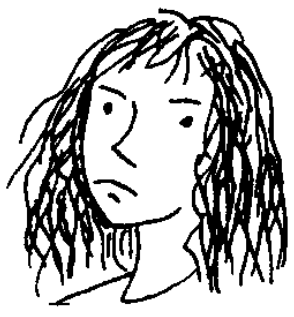

La Tina és una noia molt simpàtica, que té molts amics. El seu pare és metge i la seva mare mestra.

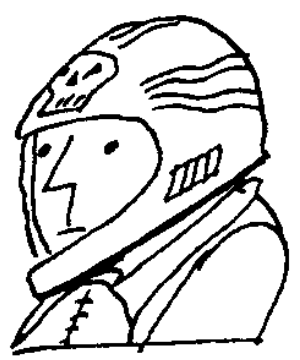

En Pere és un gran afeccionat a la jardineria. Es cuida dels jardins del seu institut i participa en concursos de flors silvestres.

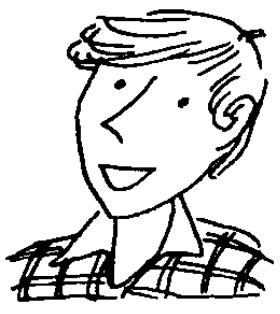

En Robert no té pares, viu amb els seus oncles però ells no l'estimen i l'obliguen a treballar, encara que no té l'edat.

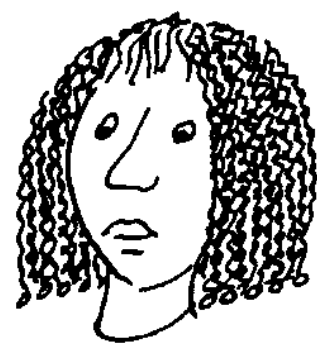

Aquesta noia es diu Berta. El seu xicot és en Pau, el noi de la primera fotografia. Els seus pares estan molt contents amb aquesta relació. 

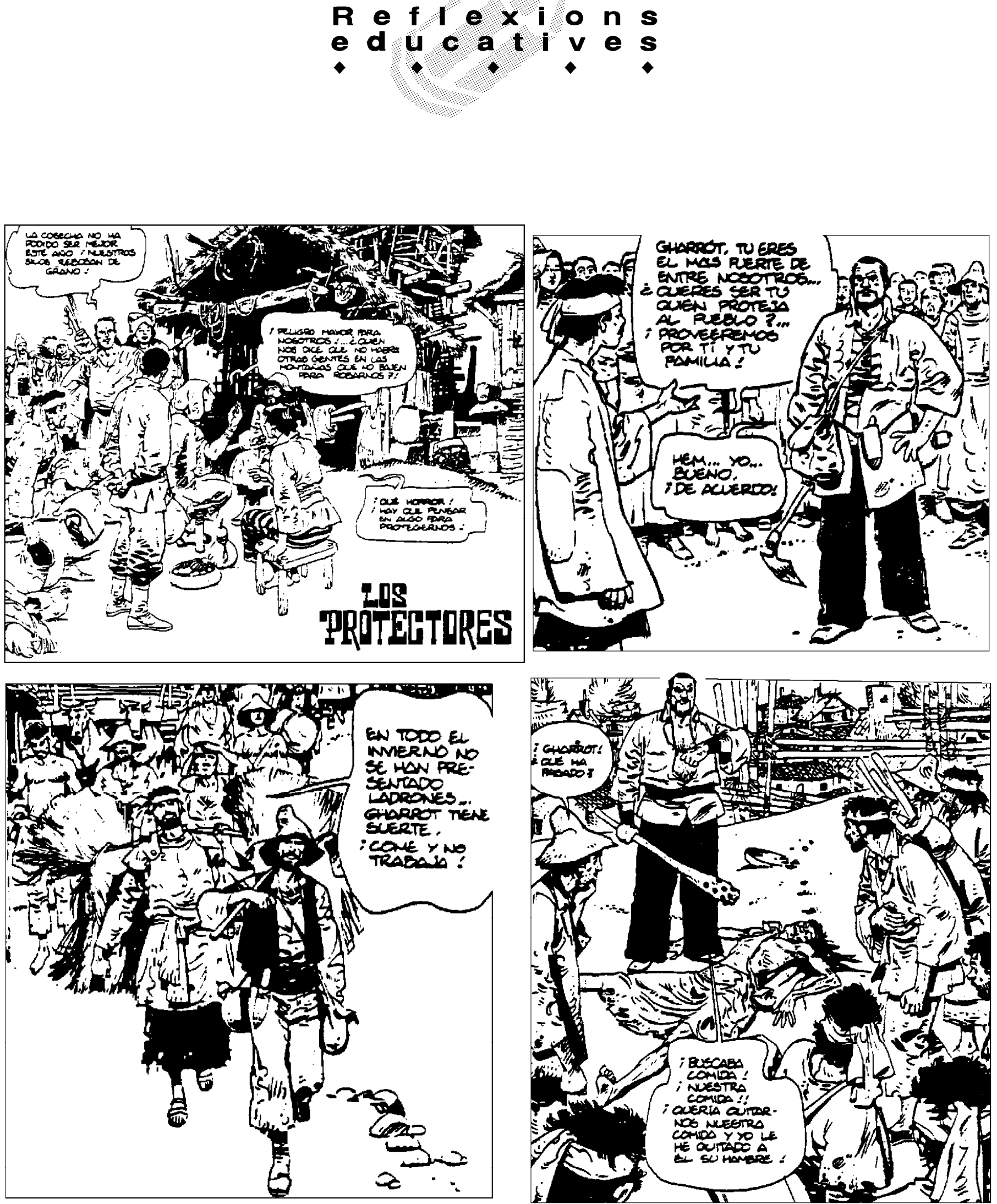

Còmic d'A. Font. Los protectores. «Totem» 5 (1977).

La identitat no s'entén sense l'alteritat, és a dir, que la nostra idiosincràsia s'explica per la nostra relació amb les persones del nostre voltant.

Interrelació. Dins d'un grup social s'estableixen relacions diverses, de vegades de comunicació, de vegades d'interdependència. El que fem afecta altres persones, les beneficia o les pot perjudicar.

Conflicte. Un dels tipus de relacions més freqüents entre les persones són els conflictes. La solució dels conflictes requereix una actitud de diàleg i de cooperació. 


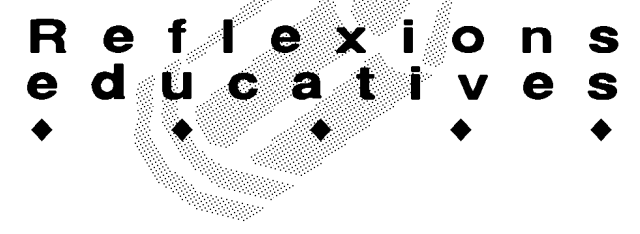

El conflicte, en principi, no és un concepte negatiu, ja que forma part de la mateixa vida dels grups.

Organització. Qualsevol grup o comunitat s'organitza de manera explícita o implícita amb les persones que el formen. D'una determinada organització, se'n deriva un concepte de llibertat i de responsabilitat. Les normes 0 les lleis regulen les organitzacions.

Poder. L'existència de democràcia dins d'un grup es mesura per la concepció del poder que hi predomina. $\mathrm{Hi}$ ha formes molt diverses de poder, d'exercir el poder, d'obtenir-lo... El poder s'explica a través del lideratge, de la repressió, de la participació...

Canvi. El present es pot analitzar en funció de l'evolució dels canvis socials i polítics del passat, de la mateixa manera que podem fer prospectiva en funció de la realitat del present i de com es treballa per provocar la seva transformació.

Creences. El funcionament dels grups humans respon sempre a uns determinats valors socials. És necessari saber valorar $\mathrm{i}$ jutjar les actuacions de les persones, tenint en compte el seu pensament quant a creences, a la seva cultura, religió, etc. És important també saber quins són els nostres valors i justificar amb coherència les nostres actituds.

Racionalitat. Les persones formem grups perquè necessitem conèixer altres persones $\mathrm{i}$ conviure $\mathrm{amb}$ elles. La nostra inquietud ens porta a la causalitat, a saber contínuament el perquè de qualsevol esdeveniment social. En aquest sentit un nen és un perfecte filòsof. Un altre aspecte que la nostra racionalitat ha d'entendre de la participació democràtica és la complexitat de món en el qual hem d'actuar. Per últim, el relativisme ens demostra que el present podia haver estat diferent i que el futur pot ser com nosaltres decidim.

\section{Molt de gust, sóc jo mateix}

Un currículum per a la participació social, basat en aquests conceptes clau, ha de facilitar, en primer lloc, l'autoconeixement i l'autoacceptació de l'alumnat, per saber quin lloc s'ocupa dins de cada grup. Es tracta de conèixer-nos nosaltres mateixos per conèixer millor les altres persones; hauríem d'evitar els estereotips a l'hora de valorar. Cal saber que un grup té uns objectius i que per aconseguir-los cada membre té una responsabilitat. D'altra banda, sense normes o lleis no és possible la convivència. Cal entendre què vol dir la llibertat $i$ a qui afecta el nostre comportament o les nostres accions.
S'han de saber solucionar conflictes, saber reivindicar i saber cedir, saber solucionar problemes socials i saber prendre decisions. La democràcia ha d'anar acompanyada de la solidaritat, per evitar les injustícies que donen lloc a grans contradiccions del seu funcionament. És necessari entendre que la democràcia és una forma d'organització que hem de millorar cada dia per no anar enrere, que és una forma de poder i que no té sentit si no l'apliquem al nostre entorn, i també dins de les institucions públiques.

Els mètodes més adequats per a la nostra proposta són els socioafectius: dilemes morals, comprensió de valors, resolució de conflictes, empatia, jocs de simulació, diàleg i debat, neutralitat activa (Martínez i Puig, 1991). D'altra banda, tal com va escriure Piaget: "Sólo la cooperación conduce a la autonomía. Por lo que respecta a la lógica, la cooperación es de entrada fuente de crítica: gracias al control mutuo, rechaza simultáneamente la convicción espontánea propia del egocentrismo y la confianza ciega en la autoridad adulta. La discusión engendra así la reflexión y la verificación objetiva». No hi ha aprenentatge si no hi ha comunicació, i no hi ha comunicació si no la facilitem al nostre alumnat. Hauríem de superar allò que Camps (1993) ha anomenat la paradoxa de l'individualisme, ja que més que mai necessitem de l'aprenentatge de la col-laboració.

\section{Referències bibliogràfiques}

ARANGUREN, J. L. Etica y política. Editorial Guadarrama. Madrid. 1963.

CAMPS, V. Paradojas del individualismo. Editorial Crítica. Barcelona. 1993.

MARTÍNEZ, M. i PUIG, J.M. (coord.). La educación moral. Perspectivas de futuro y técnicas de trabajo. Editorial Graó/ICE de la UB. Barcelona. 1991.

PAGĖS, J. i SANTISTEBAN, A. Democràcia i participació. Eumo Editorial. Senderi. Quaderns d'educació ètica. Vic. 1994.

PIAGET, J. El criterio moral en el niño. Editorial Martínez Roca. Barcelona. 1987.

SANTISTEBAN, A. Ensenyar política o fer política, és aquesta la qüestió?. "L'Avenç» 174, octubre (1993) 38-40.

SANTISTEBAN, A. Democràcia, creativitat i aprenentatge de futurs. "Guix» 210, abril (1995) 13-18.

SAVATER, F. Política para Amador. Editorial Ariel. Barcelona. 1992.

SLAUGHTER, R. Futuros. HICKS,D. (coord.). Educación para la paz. Editorial Morata/MEC. Madrid. 1991. Pàgs. 247262. 